\title{
Factors affecting the choice of drospirenone as the component of combined contraceptive pill in daily clinical practice: the results of nation-wide survey
}

\author{
Magdalena Olszanecka-Glinianowicz ${ }^{1}\left(\mathbb{D}\right.$, Violetta Skrzypulec-Plinta ${ }^{2}$ (D) \\ ${ }^{1}$ Health Promotion and Obesity Management Unit, Department of Pathophysiology, Medical Faculty in Katowice, \\ Medical University of Silesia, Katowice, Poland \\ ${ }^{2}$ Women's Health Chair, School of Health Science in Katowice, Medical University of Silesia, Katowice, Poland
}

\begin{abstract}
Objectives: The aim of the multicenter, open-label, post-marketing, observational survey was to assess doctors' preferences in choosing the progestogen component of the combined contraceptive pill (CCP) and factors affecting this choice in daily clinical practice as well as non-contraceptive reasons use of CCP containing drospirenone (CCPD) and patients' tolerance and satisfaction with the treatment.

Material and methods: This multicenter, open-label, post-marketing, survey was performed nation-wide with the participation of 222 doctors involving and 10,345 patients treated with CCPD.

The study questionnaire included questions concerning factors affecting the choice of drospirenone as a component of CCP and assessing prescription pattern of the drug as well as tolerance and satisfaction with the use of CCPD.

Results: The doctors frequently declared their choice of drospirenone as the progestogen component of CCP. The most important factors affecting the choice of drospirenone, declared by doctors, were tolerance level, consistent regulation of menstrual cycle and not causing spotting.

CCPD was prescribed to patients with irregular menstrual cycles (62.7\%) and painful menstruation (46.8\%).

During follow-up, significantly increased percentage of patients assessed the tolerance of treatment with CCPD as very $\operatorname{good}(52.5 \%$ vs $68.0 \% ; p<0.01)$ and very satisfied with its use $(61.9 \%$ vs $77.8 \%, p<0.01)$.

Conclusions: 1) Drospirenone is frequently chosen progestogen component in CCP by Polish gynecologists due to its good tolerance, consistent regulation of the menstrual cycle and no spotting in patients opinion. 2) CCPD was most frequently used in patients with irregular menstrual cycles and painful menstruation. 3) The patients were satisfied with the use CCPD and treatment was well tolerated.
\end{abstract}

Key words: combined contraceptive pill containing drospirenone; doctors' preferences; patients' satisfaction; tolerance

Ginekologia Polska 2021; 92, 9: 611-616

\section{INTRODUCTION}

CCP containing $50 \mu \mathrm{g}$ of ethylene estradiol and progestin is the method of choice in the regulation of fertility in adolescents and young women, unless there are contraindications [1-3]. CCP, apart from being used in contraception, are also used in women with excessive levels of androgens in the blood. The most common cause of excess androgens of ovarian origin is polycystic ovary syndrome (10-15\% of women of childbearing age), much less frequently the growth of thecal cells (hypotrichosis) or a hormonally active ovarian tumor. The adrenal causes of androgen excess include non-classical congenital adrenal hyperplasia, Cushing's syndrome or a tumor of the adrenal glands [4].

Apart from treating the clinical features of hyperandrogenism and the contraceptive effect, CCP exerts many other beneficial therapeutic effects, such as: regulation of menstrual cycles, elimination of symptoms occurring in the course of premenstrual syndrome, decrease of menopausal symptoms, treatment of dysmenorrhea and endometriosis, increasing bone mineral density, reduction in the incidence of functional ovarian cysts, decrease in the incidence of uterine fibroids, decrease in the incidence of ectopic pregnancies, decrease in the incidence of mastopathy, decrease

\section{Corresponding author:}

Magdalena Olszanecka-Glinianowicz

Health Promotion and Obesity Management Unit, Department of Pathophysiology , Medical University of Silesia, 18 Madyków St, 40-752 Katowice, Poland

e-mail:magolsza@gmail.com 
in the incidence of breast fibroadenomas, decrease in the incidence of chronic cystic changes in the breast, decrease in the incidence of ovarian and endometrial cancers [5-7].

The estrogen component of this tablet causes a reduction in the concentrations of free testosterone and dihydrotestosterone, as well as dehydroepiandrostenedione and androstenedione in the first month of use, it also increases the concentration of SHBG, which further reduces the availability of free androgens [8].

Progestogenic preparations have different affinities for estrogen, androgen, glucocorticoid and mineralocorticoid receptors, thus translate into differences in the clinical activity profile. In the treatment of clinical symptoms of hyperandrogenism, the influence of progestogens on the activity of androgen receptors, i.e., their degree of androgenicity of progestogens or their antiandrogenic effect, is of crucial importance [9]. Drospirenone is a fourth generation progestogen and affects the activity of progesterone receptors, showing also anti-androgenic and anti-mineralocorticoid activity $[10,11]$. Thanks to its anti-androgenic and anti-mineralocorticoid activity, drospirenone alleviates symptoms related to water retention and improves the condition of acne-prone skin better than levonogestrel [12]. Drospirenone has also been shown to be more beneficial than other progestogens in women with PCOS and on premenstrual dysphoric symptoms compared to placebo $[13,14]$.

Currently, there are no Polish data on the preferences of doctors regarding the choice of CCPD and the factors affecting them. It is also unknown how this treatment affects the continuation of therapy and how it is tolerated by the patients. Therefore, the aim of the multicenter, open-label, post-marketing, observational survey was to assess doctors' preferences in choosing the progestogen component of the contraceptive pill and factors affecting this choice in daily clinical practice. The second aim of the study was to assess non-contraceptive reasons use of CCPD as well as patients' tolerance and satisfaction with the treatment.

\section{MATERIAL AND METHODS}

Two hundred and twenty-two gynecologists participated in a nation-wide, multicenter, open-label, post-marketing, survey. They interviewed 10,345 patients treated with CCPD. The survey did not meet the criteria of a medical experiment and thus did not require Bioethics Committee approval.

The inclusion criteria for doctors were specialization in gynecology, current license to practice, having in your practice an appropriate number of patients who meet the inclusion criteria for the study, completing and signing the Application Form for the Study and sending it to Europharma.

The inclusion criteria for outpatients were being 18+ years old and the use of CCPD minimum 14 days prior to study inclusion.
The exclusion criterion was inability to obtain answers to questions contained in the survey.

The physicians participating had dual roles in the survey. They answered to the questions regarding their medical practice, filled out questionnaires for a minimum of 40 patients that fulfilled the inclusion criteria during one visit survey resulting from a clinical need of the patient.

The first part of the questionnaire included demographic data of the doctors (specialization, work experience, place of work) and data on their clinical practice [progestogen most often chosen as a component the CCP (chlormadinone acetate/cyproterone acetate/desogestrel/drospirenone/norgestimat/dienogest/gestodene/levonorgestrel), trait the progestogen that most influences its choice (antiandrogenic strength/tolerance level/ lack of spotting/no effect on body mass/consistent regulation of menstrual cycles/ /elimination of the symptoms of premenstrual syndrome/ /positive action in painful menstruation/ positive effect in endometriosis treatment/drug price)].

The second part of the questionnaire was conducted in two routine outpatient visits resulting from the needs of therapy. The part conducted during the first visit included patient demographic data (age, education level, place of residence and professional activity, staying in a steady relationship), clinical data (nutritional status, number of pregnancies and deliveries, menarche, regularity of menstrual cycles, reason for use the CCPD, previously used contraception, duration of use of current contraception and dose of drospirenone). The part conducted during the second visit (about three months from the previous visit) included data on continuing to use contraception and possible causes of discontinuation.

In addition, during both visits, the patients' opinion on tolerance of the CCPD and satisfaction with the treatment used were assessed based on a four point scale (1-difficult to accept discomfort, 2 - acceptable discomfort, 3 - good tolerance, 4 - very good-tolerance and 1 - the lack, 2 - moderate, 3 - good, 4 - very good, respectively).

Statistical analysis was performed with Statistica 12.0 software (TIBCO Software Inc., Palo Alto, CA, USA). Values of variables were presented as percentages and the mean values with standard deviations (SD). The differences between visits were compared using the $\mathrm{chi}^{2}$ test and $\mathrm{chi}^{2}$ test for trend. The value of $p<0.05$ was considered statistically significant.

\section{RESULTS \\ Doctors' therapeutic preferences}

The study group of doctors' characteristics is presented in Table 1. Drospirenone was the most frequently progestogen included in the CCP chosen by doctors participating in the study $(60,4 \%)$. The most common trait of progestogen that most influences its choice indicated by doctors were high 
tolerance levels $(76.1 \%)$, consistent regulation of menstrual cycle (59.9\%) and not causing spotting (57.2\%), Table 2.

\section{The characteristics of study patients and} tolerance as well as satisfaction with use CCPD

The study group of doctors' characteristics is presented in Table 3.

In $44.1 \%$ of patients included in the study, CCPD was used also for reasons other than contraception. Most often,

\begin{tabular}{|l|c|}
\hline Table 1. Characteristics of the study group of doctors $(\mathbf{n}=\mathbf{2 2 2})$ \\
\hline Professional experience & $\mathbf{n}(\%)$ \\
\hline $2-5$ years & $3(1.4)$ \\
\hline $6-15$ years & $58(26.1)$ \\
\hline $16-20$ years & $11(5.0)$ \\
\hline$>20$ years & $150(67.6)$ \\
\hline Workplace & $n(\%)$ \\
\hline Public hospital & $63(28.4)$ \\
\hline Private hospital & $3(1.4)$ \\
\hline Public outpatients clinic & $33(14.9)$ \\
\hline Private outpatients clinic & $24(10.8)$ \\
\hline Private practice & $99(44.6)$ \\
\hline Workplace location & $n(\%)$ \\
\hline Village & $1(0.5)$ \\
\hline City < 50,000 residents & $62(27.9)$ \\
\hline City 50-200,000 residents & $61(27.5)$ \\
\hline City $>$ 200,000 residents & $98(44.1)$ \\
\hline
\end{tabular}

these reasons were irregular menstrual cycles (62.7\%) and painful menstruation (46.8\%). $16.5 \%$ of the observed patients previously used CCP containing another progestogen, most often levonorgestrel (20.2\%) - data not shown. The most common cause of changes in the pill used were no benefit effect on accompanying symptoms (30.3\%) — data not shown. $41.8 \%$ of the observed group used CCPD for 2-3 months. $98.3 \%$ of patients used CCPD at a dose of $3 \mathrm{mg}$ (Table 3).

The second visit was implemented on average 70 days after first visit. The use of the CCPD was continued by $95.8 \%$ of the observed patients. Among the $4.2 \%$ of patients that discontinued its use, the most common reasons were deliberate decision not to implement prescription (33.7\%), deliberate withdrawal of the drug due to discomfort with its' using (23.4\%), deciding to terminate treatment under the influence of other people (14.9\%) and no beneficial effects on accompanying symptoms (12.4\%).

During follow-up, significantly increased percentage of patients assessed the tolerance of treatment with CCPD as very good $(52.5 \%$ vs $68.0 \% ; p<0.01)$ and very satisfied with its use $(61.9 \%$ vs $77.8 \%, p<0.01)$. While the percentage of patients who would recommend this form of contraception to a friend was similar (98.3\% vs $99.9 \%)$, Table 4.

During follow-up in the study group, 12 adverse events in six patients $(0.06 \%$ of the observed groups) have been reported. One of these adverse events, venous thrombosis of the lower extremities, was serious (Tab. 5).

\begin{tabular}{|c|c|c|c|}
\hline Progestogen chosen as a component the CCP [\%] & Rarely & Often & The most common \\
\hline Chlormadinone acetate & 47.3 & 50.9 & 1.8 \\
\hline Cyproterone acetate & 81.5 & 17.6 & 0.9 \\
\hline Desogestrel & 40.1 & 53.6 & 6.3 \\
\hline Drospirenone & 2.3 & 37.4 & 60.4 \\
\hline Norgestimat & 43.2 & 55.9 & 0.9 \\
\hline Dienogest & 22.1 & 70.3 & 7.7 \\
\hline Gestodene & 36.5 & 48.2 & 15.3 \\
\hline Levonorgestrel & 32.0 & 62.6 & 5.4 \\
\hline Trait the progestogen decides about its choice [\%] & Not important & Important & Very important \\
\hline Antiandrogenic strength & 5.0 & 65.3 & 29.7 \\
\hline Good tolerance & 0.5 & 23.4 & 76.1 \\
\hline The lack of spotting & 9.0 & 33.8 & 57.2 \\
\hline No effect on body mass & 3.6 & 45.0 & 51.4 \\
\hline Very good regulation of menstrual cycles & 7.7 & 32.4 & 59.9 \\
\hline Very good elimination of the symptoms of premenstrual syndrome & 13.5 & 45.9 & 40.5 \\
\hline Very good action in painful menstruation & 6.3 & 43.2 & 50.5 \\
\hline Very good effect in endometriosis treatment & 23.9 & 60.4 & 15.8 \\
\hline Drug price & 33.8 & 60.4 & 5.9 \\
\hline
\end{tabular}


Table 3. Characteristics of patients study groups treated with CCPD $(n=10.345)$

\section{Sociodemographic}

Age (years) (mean $\pm S D)(\min -\max )$

$28 \pm 7(18-52)$

Education levels

(\%)

Primary

$325(3.1)$

Vocational

$1.142(11.0)$

Secondary

$5.379(52.0$

Higher

$3.499(33.8)$

Professional activity

n (\%)

Working

$6.711(64.9)$

Not working

1.025 (9.9)

Pension

$27(0.3)$

Student

$2.582(25.0)$

Staying in a solid relationship:

$7.216(69.8)$

Clinical

\begin{tabular}{|c|c|}
\hline Nutritional status & n (\%) \\
\hline Underweight & $717(6.9)$ \\
\hline Normal weight & $7.795(75.4)$ \\
\hline Overweight & $1.712(16.5)$ \\
\hline Obesity & $121(1.2)$ \\
\hline Number of pregnancies & n (\%) \\
\hline 0 & $4.820(46.6)$ \\
\hline 1 & $2.335(22.6)$ \\
\hline 2 & $2.079(20.1)$ \\
\hline$>2$ & $1.111(10.7)$ \\
\hline Number of births & n (\%) \\
\hline 0 & $4.912(47.5)$ \\
\hline 1 & $2.665(25.8)$ \\
\hline 2 & $2.183(21.1)$ \\
\hline$>2$ & $585(5.7)$ \\
\hline Age of menarche & n (\%) \\
\hline $10-11$ years & $1.074(10.4)$ \\
\hline $12-14$ years & $8.211(79.4)$ \\
\hline$>14$ years & $1.060(10.2)$ \\
\hline Regularity of menstrual cycles & n (\%) \\
\hline Regular & $6.763(65.4)$ \\
\hline Irregular & $3.527(34.1)$ \\
\hline Secondary amenorrhea & $55(0.5)$ \\
\hline Non-contraceptive reason to use the CCPD & $5.787(55.9)$ \\
\hline $\begin{array}{l}\text { The factors determining the choice of } \\
\text { drospirenone }\end{array}$ & n (\%) \\
\hline Hyperandrogenism & $1.039(22.8)$ \\
\hline Overweight & $390(8.6)$ \\
\hline Irregular menstrual cycles & $2.858(62.7)$ \\
\hline Premenstrual syndrome & $1.180(25.9)$ \\
\hline Painful menstruation & $2.131(46.8)$ \\
\hline
\end{tabular}

Table 3. Characteristics of patients study groups treated with CCPD ( $n=10.345$ ) (continued)

\begin{tabular}{|l|c|}
\hline Endometriosis & $172(3.8)$ \\
\hline Abundant menstruation & $43(0.9)$ \\
\hline Acne & $28(0.6)$ \\
\hline Other & $21(0.5)$ \\
\hline Duration of taking the CCPD & $\mathbf{n}(\%)$ \\
\hline$<1$ month & $1.617(15.6)$ \\
\hline $2-3$ months & $4.327(41.8)$ \\
\hline $4-6$ months & $1.960(18.9)$ \\
\hline $7-12$ months & $1.250(12.1)$ \\
\hline$>12$ months & $1.191(11.5)$ \\
\hline Drospirenone dose used & $\mathbf{n}(\%)$ \\
\hline 3 mg & $10.172(98.3)$ \\
\hline 2 mg & $173(1.7)$ \\
\hline
\end{tabular}

\section{DISCUSSION}

More than half of the doctors participating in the study indicated drospirenone as the most frequently chosen progestogen in the CCP. The most frequently indicated features of the active substance determining its selection were tolerance level, consistent regulation of the menstrual cycles and no spotting. The importance of the non-contraceptive effects of the CCPD for doctors is confirmed by the fact that over $40 \%$ of patients included in the study also used it for reasons other than contraception. The most common reasons were irregular menstrual cycles and painful menstruation, which is consistent with the features indicated as important when choosing a progestogen included in the CCP. Moreover, the most common changes in the contraceptive use were made due to the lack of a beneficial effect on the accompanying symptoms. The progestogen most often changed to drospirenone was levonorgestrel. While, the results of a randomized study showed that the CCPD is more effective at relieving the symptoms of painful periods than the pill containing chlormadinone [15]. It should also be noted that in 2010 in Great Britain, similarly to the presented study, in over $40 \%$ of women the CCPD was used for non-contraceptive reasons [16].

During the follow-up, the use of the CCPD was continued by $95.8 \%$ of the observed patients. Moreover, the percentage of patients assessing the tolerance of the CCPD used as "very good"increased significantly. It should be noted that $98.3 \%$ of study women were treated with pills containing $3 \mathrm{mg}$ drospirenone. High tolerance of the drug is also confirmed by the fact that adverse events were reported in $0.06 \%$ of the studied group, just one adverse event was severe. The rate of adverse 


\begin{tabular}{|l|c|c|c|}
\hline \multicolumn{4}{|l|}{ Table 4. Changes of tolerance and satisfaction of the patients during observation } \\
\hline
\end{tabular}

NS: non-statistical

\begin{tabular}{|l|l|}
\hline Table 5. Adverse events related to treatment with CCPD \\
\hline Adverse event & $\mathbf{n}$ \\
\hline Intolerance & 2 \\
\hline Decline in libido & 3 \\
\hline Venous thrombosis of the lower extremities & 1 \\
\hline Calf pain & 2 \\
\hline Constant spotting & 1 \\
\hline Periodic spotting & 1 \\
\hline Swelling of the breasts & 1 \\
\hline Slight swelling of the ankles & 1 \\
\hline Total & 12 \\
\hline
\end{tabular}

events was much lower than observed in another study. In this study was $1.5 \%$, after subtracting the placebo effect, discontinued the use of CCP containing $3 \mathrm{mg}$ drospirenone [17]. The differences may be the results of the lower number of study women $(n=266)$ and the indication for the use of CCP (moderate facial acne), the duration of the treatment as well as nature of the study (a randomized, double — blind, controlled placebo vs observational study carried out in the conditions of everyday clinical practice). The high tolerance treatment with CCPD has also been observed in group young adult women with primary dysmenorrhea [18].

During the follow-up, the percentage of patients who were very satisfied with the use of CCPD increased significantly. The percentage of patients recommending this form of contraception to a friend has also increased slightly. Satisfaction with the use of this contraceptive pill may be related not only to its contraceptive efficacy and good tolerability, but also, as suggested by the results of a previously published study with improvement in well-being at the time of application these pills and its deterioration after discontinuation [19]. It is also suggested that the use of a CCP may improve the quality of life [20].

The conducted study describing the daily clinical practice of Polish gynecologists in the use of CCP confirms previous observations on the benefits of using the fourth generation progestogen - drospirenone as a component of CCP [17-20], improves the continuation of contraception and positively affects the quality of life of patients. This may be an indication for doctors that in the event of low tolerance of CCP containing another progestogen, switching to CCPD will encourage the patient to continue the therapy. This is especially important in the group of patients using CCP for other than contraceptive reasons.

The main limitation of the presented study is the lack of control group treated with placebo and the lack of comparisons with CCP containing other progestogens. However, the strengths of the study are study group size and assessment of daily clinical practice.

\section{CONCLUSIONS}

Drospirenone is frequently chosen as the progestogen component in CCP by Polish gynecologists due to its good tolerance, consistent regulation of the menstrual cycle and no spotting in patients opinion.

CCPD was most frequently used in patients with irregular menstrual cycles and painful menstruation.

The patients were satisfied with the use CCPD and treatment was well tolerated.

\section{Conflict of interest}

Magdalena Olszanecka-Glinianowicz received honorarium for study concept from Europharma.

Violetta Skrzypulec-Plinta received honorarium for co-edition from Europharma. 


\section{Acknowledgments}

The study was carried out as a research project supported by scientific grant of Adamed Pharma organized by Europharma M. Rachtan Sp. z o.o. Poland

\section{REFERENCES}

1. Rekomendacje Polskiego Towarzystwa Ginekologicznego dotyczące antykoncepcji hormonalnej - stan na rok 2006. Ginekologia po Dyplomie. 2006: 27-31.

2. World Health Organization Contraception in adolescence. World Health Organization Library Cataloguing-in-Publication Data, Geneva 2004.

3. French RS, Cowan FM. Contraception for adolescents. Best Pract Res Clin Obstet Gynaecol. 2009; 23(2): 233-247, doi: 10.1016/j.bpobgyn.2008.12.002, indexed in Pubmed: 19171502.

4. Azziz R, Carmina E. Criteria for defining polycystic ovary syndrome as a predominantly hyperandrogenic syndrome: an Androgen Excess Society Guideline. Position statement. J Clin Endocrinol Metab. 2006; 91(11): 4237-4245, doi: 10.1210/jc.2006-0178, indexed in Pubmed: 16940456.

5. Burkman R, Schlesselman J, Zieman M. Safety concerns and health benefits associated with oral contraception. American Journal of Obstetrics and Gynecology. 2004; 190(4): S5-S22, doi: 10.1016/j.ajog.2004.01.061.

6. Pertyński T, Stachowiak G. Niskodawkowa, dwuskładnikowa doustna antykoncepcja u kobiet w okresie pre-i okołomenopauzalnym. Przegląd Menopauz. 2006; 4: 257-264.

7. Rosenberg L, Palmer JR, Zauber AG, et al. A case-control study of oral contraceptive use and invasive epithelial ovarian cancer. Am J Epidemiol. 1994; 139(7):654-661, doi: 10.1093/oxfordjournals.aje.a117055, indexed in Pubmed: 8166126.

8. White T, Jain JK, Stanczyk FZ. Effect of oral versus transdermal steroidal contraceptives on androgenic markers. Am J Obstet Gynecol. 2005; 192(6): 2055-2059, doi:10.1016/j.ajog.2005.02.067, indexed in Pubmed: 15970897.

9. Simoncini T, Genazzani AR. A review of the cardiovascular and breast actions of drospirenone in preclinical studies. Climacteric. 2009; 13(1): 22-33, doi: 10.3109/13697130903437375.

10. Sitruk-Ware $\mathrm{R}, \mathrm{Nath} \mathrm{A}$. The use of newer progestins for contraception. Contraception. 2010; 82(5): 410-417, doi: 10.1016/j.contraception.2010.04.004, indexed in Pubmed: 20933114.

11. Krattenmacher R. Drospirenone: pharmacology and pharmacokinetics of a unique progestogen. Contraception. 2000; 62(1): 29-38, doi: 10.1016/s0010-7824(00)00133-5, indexed in Pubmed: 11024226.
12. Kelly S, Davies E, Fearns S, et al. Effects of oral contraceptives containing ethinylestradiol with either drospirenone or levonorgestrel on various parameters associated with well-being in healthy women: a randomized, single-blind, parallel-group, multicentre study. Clin Drug Investig. 2010; 30(5): 325-336, doi: 10.2165/11535450-000000000-00000, indexed in Pubmed: 20384388

13. Kriplani A, Periyasamy AJ, Agarwal N, et al. Effect of oral contraceptive containing ethinyl estradiol combined with drospirenone vs. desogestrel on clinical and biochemical parameters in patients with polycystic ovary syndrome. Contraception. 2010; 82(2): 139-146, doi: 10.1016/j. contraception.2010.02.009, indexed in Pubmed: 20654754.

14. Marr J, Heinemann $K$, Kunz M, et al. Ethinyl estradiol $20 \mu \mathrm{g} /$ drospirenone $3 \mathrm{mg} 24 / 4$ oral contraceptive for the treatment of functional impairment in women with premenstrual dysphoric disorder. Int J Gynaecol Obstet. 2011; 113(2): 103-107, doi: 10.1016/j.ijgo.2010.10.029, indexed in Pubmed: 21338987.

15. Jaisamrarn U, Santibenchakul S. A comparison of combined oral contraceptives containing chlormadinone acetate versus drospirenone for the treatment of acne and dysmenorrhea: a randomized trial. Contracept Reprod Med. 2018; 3: 5, doi: 10.1186/s40834-018-0058-9, indexed in Pubmed: 29662684

16. Cea-Soriano L, Wallander MA, García Rodríguez LA. Prescribing patterns of combined hormonal products containing cyproterone acetate, levonorgestrel and drospirenone in the UK. J Fam Plann Reprod Health Care. 2016; 42(4): 247-254, doi: 10.1136/jfprhc-2015-101202, indexed in Pubmed: 27098200

17. Koltun W, Lucky AW, Thiboutot $D$, et al. Efficacy and safety of $3 \mathrm{mg}$ drospirenone/20 mcg ethinylestradiol oral contraceptive administered in 24/4 regimen in the treatment of acne vulgaris: a randomized, double-blind, placebo-controlled trial. Contraception. 2008; 77(4): 249-256, doi: 10.1016/j.contraception.2007.11.003, indexed in Pubmed: 18342647.

18. Al-Jefout M, Nawaiseh N. Continuous Norethisterone Acetate versus Cyclical Drospirenone $3 \mathrm{mg} /$ Ethinyl Estradiol $20 \mu \mathrm{g}$ for the Management of Primary Dysmenorrhea in Young Adult Women. J Pediatr Adolesc Gynecol. 2016; 29(2): 143-147, doi: 10.1016/j.jpag.2015.08.009, indexed in Pubmed: 26342733.

19. Boschitsch E, Skarabis H, Wuttke W, et al. The acceptability of a novel oral contraceptive containing drospirenone and its effect on well-being Eur J Contracept Reprod Health Care. 2000; 5 Suppl 3: 34-40, indexed in Pubmed: 11246600.

20. Dickerson V. Quality of life issues. Potential role for an oral contraceptive containing ethinyl estradiol and drospirenone. J Reprod Med. 2002; 47(11 Suppl): 985-993, indexed in Pubmed: 12497673. 